\title{
Cross-Sectional and Longitudinal Associations of Neighborhood Cohesion and Stressors with Depressive Symptoms in the Multiethnic Study of Atherosclerosis
}

\author{
CHRISTINA MAIR, MPH, ANA V. DIEZ ROUX, MD, PHD, MPH, MINGWU SHEN, MS, \\ STEVEN SHEA, MD, MS, THERESA SEEMAN, PHD, SANDRA ECHEVERRIA, PHD, \\ AND ELLEN S. O’MEARA, PHD
}

\begin{abstract}
PURPOSE: This study examined associations of neighborhood social cohesion, violence, and aesthetic quality with depressive symptoms among 2,619 healthy adults aged 45-84 years enrolled in the Multiethnic Study of Atherosclerosis.

METHODS: Neighborhood characteristics were estimated by surveying a separate sample of area residents. Measures of aesthetic environment, social cohesion, and violence were combined into a summary score with increasing scores indicating more favorable environments. Depressive symptoms were measured using the Center for Epidemiologic Studies-Depression (CES-D) scale. Marginal maximum likelihood estimation was used to assess associations of neighborhood characteristics with CES-D score at baseline and with the odds of developing incident depression (CES-D score $\geqslant 16$ or use of antidepressants) over a 4-5 year follow-up among persons with CES-D less than 16 at baseline. Models were adjusted for age, income, education, and race/ethnicity.

RESULTS: Lower levels of social cohesion and aesthetic quality and higher levels of violence were associated with higher mean CES-D scores in men and women $(P$ for trend $<0.01$, adjusted mean difference in CES-D per 1 SD increase in summary score -1.01 [95\% confidence interval $=-1.85,-0.17$ ] and -1.08 $[95 \%$ confidence interval $=-1.88,-0.28]$ in men and women, respectively). Associations of neighborhood characteristics with incident depression were in the expected direction for women but confidence intervals were wide (odds ratio of incident depression $=0.89[0.63,1.26]$ ). No association was seen for men (odds ratio $=0.96[0.74,1.25])$.
\end{abstract}

CONCLUSION: Neighborhood social cohesion, aesthetic quality, and violence are associated with the presence of depressive symptoms in residents.

Ann Epidemiol 2009;19:49-57. (C) 2008 Elsevier Inc. All rights reserved.

KEY wORDS: Mental Health, Depression, Residence Characteristics, Epidemiology, Social Environment.

\section{INTRODUCTION}

There has been growing interest in understanding the effects of neighborhood conditions on psychological well-being (1). It has been hypothesized that contextual characteristics of neighborhoods may be related to mental health outcomes, above and beyond the effects of individual characteristics. The majority of studies of neighborhood characteristics and depressive symptoms have focused on the effects of area socioeconomic position, after controlling for

From the Center for Social Epidemiology and Population Health, Department of Epidemiology, University of Michigan, Ann Arbor (C.M., A.V.D.R., M.S.); Departments of Medicine and Epidemiology, Columbia University, New York (S.S.); Departments of Medicine and Epidemiology, Geffen School of Medicine at UCLA, Los Angeles, California (T.S.); ${ }^{4}$ Department of Epidemiology, UMDNJ School of Public Health, New Brunswick, New Jersey (S.E.); and Department of Biostatistics, University of Washington, Seattle (E.S.O.M.).

Address correspondence to: Ana V. Diez Roux, MD, PhD, University of Michigan, Center for Social Epidemiology and Population Health, 3rd Floor SPH Tower, 109 South Observatory, Ann Arbor, MI 48109-2029. Tel.: 734-615-9204; fax: 734-998-0006. E-mail: adiezrou@umich.edu.

Received April 11, 2008; accepted October 16, 2008. individual-level characteristics. Most (2-9), although not all (10-13), of these studies have documented a small contextual effect of low neighborhood or area socioeconomic conditions on depressive symptoms. Although useful as an initial approximation, this approach has methodologic limitations related to difficulties in isolating true contextual effects $(14,15)$ and the inability to identify the specific contextual characteristics that are relevant (15).

A relatively small number of studies have investigated associations between specific features of the local environment (such as residential instability, racial/ethnic composition, perceived ambient hazards, or a poor quality physical environment) and depressive symptoms: some have documented a small but statistically significant association (1, 5-8, 16-21) whereas others have not (12). Many studies use the same study population to measure depressive symptoms and neighborhood conditions $(5,6,18-22)$. This can create spurious associations (sometimes referred to as same-source bias) because a depressed person might see his or her neighborhood in a more negative light than someone exhibiting no depressive symptoms. In addition, the 


\section{Selected Abbreviations and Acronyms}

CES-D $=$ Center for Epidemiologic Studies-Depression scale MESA $=$ Multi-Ethnic Study of Atherosclerosis

majority of work has been cross-sectional with only a small number of studies investigating longitudinal associations (23). An important limitation of cross-sectional analyses is that they are limited in their ability to determine the direction of causality (i.e., neighborhood characteristics causing depression vs. depression causing individuals to live in certain kinds of neighborhoods). Hence, longitudinal analyses are needed.

Using data from the Multi-Ethnic Study of Atherosclerosis (MESA), a large, population-based cohort study, we examined cross-sectional and prospective associations of three measures of specific neighborhood characteristics with depressive symptoms, among healthy adults 45-84 years of age. We hypothesized that low levels of neighborhood social cohesion and high levels of neighborhood stressors would be associated with higher levels of depressive symptoms as well as with increases in depressive symptoms over time, after adjustment for individual socioeconomic characteristics. In measuring neighborhood social cohesion and stressors we used validated scales and data from a survey of non-MESA participants who resided in the same neighborhoods as members of the cohort. The use of these measures avoids same-source bias and increases the validity of measures by aggregating responses across several respondents thus reducing variability due to individual subjectivity and measurement error (24).

\section{METHODS}

\section{Study Setting and Population}

Information on depressive symptoms and relevant covariates was obtained from participants in MESA, a 10-year longitudinal study of men and women 45-84 years of age. Participants were enrolled at six study field centers between August 1, 2000 and July 30, 2002 using population-based approaches. Participants were free of clinical cardiovascular disease at enrollment (25). The participation rate among those screened and deemed eligible was 58\%. Analyses reported in this study are restricted to participants residing at three of six MESA sites (Baltimore, MD, Forsyth County, NC, and New York City, NY) because these are the three sites where additional neighborhood-level data were collected. Institutional review boards at all participating study centers approved the study, and informed consent was obtained from all study participants.

Information on neighborhood characteristics was collected using a phone survey from a separate sample of persons who resided in the same geographic areas as MESA participants (henceforth referred to as the community survey) (24). The community survey was conducted by a subcontracted firm specializing in survey research. Survey respondents serve as informants of neighborhood conditions in neighborhoods where MESA participants reside. These variables were linked to MESA participants by census tract, a method that has been used in previous studies (24, 26). Between January and August 2004, 5,988 people living in the same census tracts as the MESA participants in Baltimore, New York City, and Forsyth County were selected through random-digit-dialing with a median of eight survey respondents per tract (range: 1-62 participants). The purpose of the community survey was to construct measures of neighborhood-level properties for these areas, which could be linked to MESA participants. The participation rate in the survey was $46.5 \%$. The community survey sample was approximately representative of the geographic areas sampled (24).

\section{Data Collection}

Depressive symptoms were measured in MESA participants at baseline and at two follow-up visits, one 3-4 years after baseline and the other $4-5$ years after baseline, using the 20-item Center for Epidemiologic Studies-Depression (CES-D) Scale (27). Each scale item is scored from 0-3, with a higher score representing more depressive symptoms. The potential range of this scale is $0-60$, with a score of 16 often used as a screening cutoff for clinical depression.

The main covariates used in the analysis included gender, age, race/ethnicity, annual income, and highest level of education achieved, all assessed at the MESA baseline exam via questionnaire. Age was categorized into four groups (45-54, 55-64, 65-74, 75-84). Race and ethnicity were classified as Caucasian, African American, and Hispanic, based on self-report using questions from the Year 2000 U.S. Census. Total gross family income was categorized into five levels: less than $\$ 20,000, \$ 20,000-34,999$, $\$ 35,000-49,999, \$ 50,000-74,999$, and $\$ 75,000$ or more. Education was categorized as: less than high school, completed high school, some college or a trade or Associate degree, Bachelor degree, and graduate/professional degree.

Community survey respondents were asked to assess certain features of their neighborhood (a 1-mile area around their home). This distance was selected because it has been used commonly in prior work measuring neighborhoods. Scales were used to assess neighborhood social cohesion (constructed from four items) $(24,28)$ and two domains related to the construct of neighborhood stressors: violence (four items) $(24,28)$ and aesthetic quality (six items) $(24)$. The internal consistency of the three scales was high (Cronbach's $\alpha=0.75$ [aesthetic quality], 0.83 [violence], 0.74 
[social cohesion]). All three scales also had acceptable ecometric properties, i.e., they were reliable measures of area-level constructs and were related to other neighborhood-level properties in the expected direction (24). Social cohesion has been hypothesized to be a social resource that may strengthen mental health $(18,21)$. Violence and poor aesthetic quality were included as potential neighborhood stressors. The presence and perceptions of violence have been linked to psychological distress $(6,20,22)$. The physical environment has also been hypothesized to influence psychosocial stress: specific elements of a poor aesthetic environment, such as a lack of green space, have been found to be associated with increased levels of stress $(16,17,19,29,30)$. With the exception of the violence scale, increasing scores represent a more favorable neighborhood environment.

\section{Data Analysis}

Analyses were stratified by gender, as previous research has shown that the prevalence of depression and depressive symptoms differs between men and women (31), and because depressive symptoms in men and women may be differentially affected by neighborhood environments (23). We initially examined the unadjusted cross-sectional associations between each of the three neighborhood characteristics and depression at baseline using plots, smooth regression lines (32), and by estimating CES-D means for quartiles of each neighborhood indicator and testing for a trend across categories. In these analyses, we used unconditional Empirical Bayes estimates of the neighborhood score for each census tract. Census tracts have been used commonly in similar analyses as proxies for neighborhoods (23). Empirical Bayes estimates are obtained by calculating a weighted average of the crude mean for each neighborhood and the crude mean across all neighborhoods in the study, where the weights are proportional to the reliability of the neighborhood measure. This is better than using a simple crude mean estimate for each neighborhood census tract, as it allows neighborhoods with less reliable data to borrow information from other neighborhoods, to improve the estimate (33). Each neighborhood measure was transformed into units of standard deviations (for the full sample), to allow comparisons across scales. Because associations with the CES-D score were similar for all three indicators, and because the three neighborhood level measures were highly correlated (Pearson correlation coefficient range $=0.70-0.79$ ), we also created a summary index of the three neighborhood characteristics for each participant. As in prior studies $(12,34)$, this summary index was created by summing the $z$ scores of aesthetic environment, social cohesion, and violence. The violence scale was reversed in calculating the summary index, so that a higher score reflected less violence. Intraclass correlation coefficients for CES-D scores within neighborhoods were estimated by fitting a multilevel model with a random intercept for each neighborhood.

Linear regression was used to examine cross-sectional associations of neighborhood characteristics with depression before and after adjustment for individual-level variables. CES-D was investigated as a continuous variable because it was not highly skewed. We used marginal maximum likelihood estimation methods to estimate parameters, because this allows for simultaneous modeling of data from the MESA sample and the community survey sample (35), and accounts for random error in neighborhood-level predictors due to sampling variability. These models also account for residual correlation within neighborhoods. Models included age, race/ethnicity, income, education, and neighborhood-level characteristics, both separately and in the form of the summary score. All models were fitted using SAS Proc Nlmixed (SAS Version 9.1. SAS Institute Inc., Cary, NC)(35).

Analogous logistic regression models were used to examine the association of neighborhood conditions with the onset of depression (defined as CES-D $\geqslant 16$ or use of antidepressant medications during follow-up). All participants with a CES-D score of 16 or greater or who were on antidepressant medications at baseline were excluded from these analyses, as well as participants with missing CES-D scores at either follow-up period. Similar results were observed when survival analysis instead of logistic regression was used. We also obtained similar results when random effects models were used to model repeat CES-D measures and differences in changes over time associated with neighborhood characteristics using the whole sample (i.e., not restricted to those with CES-D $<16$ at baseline). However, because these repeat measures models cannot yet be fit with the marginal maximum likelihood estimation method, only the simpler logistic regression results are presented in this study.

A total of 2,963 participants from three study sites participated in the MESA study. Of these 2,963 participants, 27 were excluded because they had no CES-D score at baseline. An additional 149 were missing information about other covariates. An additional 198 of the remaining participants were missing neighborhood-level data leaving a total of 2,609 participants for cross-sectional analysis. These participants lived in 1,188 census tracts, with a median of two residents per tract $(25 \%=1,75 \%=5)$. Longitudinal analyses were further restricted to 1,919 participants with CES-D scores less than 16 at baseline who were not using antidepressants and with CES-D information at both follow-up visits.

\section{RESULTS}

Table 1 shows the distribution of selected individual- and neighborhood-level characteristics by gender. Approximately 
TABLE 1. Selected individual- and neighborhood-level characteristics of MESA study participants at baseline (2000-2002)

\begin{tabular}{|c|c|c|c|}
\hline Characteristics & $\begin{array}{l}\text { All participants } \\
(n=2,609)\end{array}$ & $\begin{array}{l}\text { Men } \\
(n=1,196)(\end{array}$ & $\begin{array}{c}\text { Women } \\
(n=1,413)\end{array}$ \\
\hline \multicolumn{4}{|l|}{ Individual-level } \\
\hline \multicolumn{4}{|l|}{ Study site (\% distribution) } \\
\hline Forsyth County, NC & 32.0 & 32.5 & 31.6 \\
\hline New York, NY & 34.8 & 33.1 & 36.1 \\
\hline Baltimore, MD & 33.2 & 34.4 & 32.3 \\
\hline \multicolumn{4}{|l|}{ Race/ethnicity (\% distribution) } \\
\hline Caucasian & 42.3 & 44.9 & 40.2 \\
\hline African American & 41.6 & 39.2 & 43.7 \\
\hline Hispanic & 16.0 & 15.9 & 16.2 \\
\hline \multicolumn{4}{|l|}{ Age (years) (\% distribution) } \\
\hline $45-54$ & 28.1 & 26.5 & 29.6 \\
\hline $55-64$ & 28.4 & 28.4 & 28.4 \\
\hline $65-74$ & 31.0 & 32.2 & 29.9 \\
\hline $75-84$ & 12.5 & 13.0 & 12.1 \\
\hline \multicolumn{4}{|l|}{ Annual income (\% distribution) } \\
\hline$<20,000$ & 19.0 & 13.7 & 23.5 \\
\hline $20,000-34,999$ & 20.9 & 16.8 & 24.3 \\
\hline $35,000-49,999$ & 18.1 & 17.7 & 18.5 \\
\hline $50,000-74,999$ & 20.1 & 23.0 & 17.6 \\
\hline $75,000+$ & 21.9 & 28.7 & 16.1 \\
\hline \multicolumn{4}{|l|}{ Education (\% distribution) } \\
\hline$<$ High school & 13.6 & 13.4 & 13.7 \\
\hline Completed high school & 20.6 & 18.3 & 22.5 \\
\hline Some college/associate/trade & 29.3 & 25.6 & 32.4 \\
\hline Bachelor degree & 18.3 & 20.7 & 16.3 \\
\hline $\begin{array}{l}\text { Graduate/professional } \\
\text { degree }\end{array}$ & 18.3 & 22.0 & 15.1 \\
\hline \multicolumn{4}{|l|}{ Neighborhood-level } \\
\hline $\begin{array}{l}\text { Social cohesion } \\
\quad(\text { mean },(S D))^{*}\end{array}$ & $3.18(0.32)$ & $3.20(0.31) 3$ & $3.17(0.32)$ \\
\hline Violence $(\text { mean }(\mathrm{SD}))^{\dagger}$ & $1.92(0.39)$ & $1.90(0.38) 1$ & $1.93(0.39)$ \\
\hline $\begin{array}{l}\text { Aesthetic environment } \\
\quad(\text { mean }(\mathrm{SD}))^{\ddagger}\end{array}$ & $3.85(0.45)$ & $3.87(0.44) 3$ & $3.83(0.45)$ \\
\hline $\begin{array}{l}\text { Summary index } \\
(\text { mean }(\mathrm{SD}))^{\S}\end{array}$ & $0.02(1.00)$ & $0.07(0.99)-$ & $-0.03(1.01)$ \\
\hline
\end{tabular}

MESA = Multi-Ethnic Study of Atherosclerosis

*Social cohesion scale includes the following items: 1) people around here are willing to help their neighbors; 2) people in my neighborhood generally get along with each other; 3) people in my neighborhood can be trusted; and 4) people in my neighborhood share the same values.

${ }^{\dagger}$ Violence scale includes the following items: During the past 6 months, how often: 1 ) was there a fight in your neighborhood in which a weapon was used;2) were there gang fights in your neighborhood; 3) was there a sexual assault or rape in your neighborhood; and 4) was there a robbery or mugging in your neighborhood. A higher score indicates a less favorable environment for the violence scale.

${ }^{\ddagger}$ Aesthetic environment scale includes the following items: 1 ) there is a lot of trash and litter on the street in my neighborhood; 2) there is a lot of noise in my neighborhood; 3) in my neighborhood the buildings and homes are well-maintained; 4) the buildings and houses in my neighborhood are interesting; and 5) my neighborhood is attractive.

${ }^{\S}$ Summary index based on summed $Z$ scores for Empirical Bayes estimates of social cohesion, violence, and aesthetic environment. A higher score indicates a more favorable neighborhood environment.

$13 \%$ of participants were in the oldest age category (75-84) with the rest being approximately distributed evenly across categories. The annual income and mean level of education of women were lower than those of men (Table 1). Intraclass correlation coefficients for CES-D scores within each neighborhood were $7.8 \%$ in women and $9.8 \%$ in men (not shown in table).

Table 2 shows the mean CES-D score for men and women, by quartiles of neighborhood social cohesion, violence, aesthetic environment, and the summary score. Lower levels of social cohesion and aesthetic quality and higher levels of violence were associated with higher mean CES-D scores in both men and women ( $P$ for trend $<0.01$ for all). Mean CES-D score decreased with increasing quartiles of the index summary score $(P$ for trend $<0.01)$. Associations appeared linear with no clear evidence of a threshold effect. In general, the associations were stronger in women than in men for all measures, as evidenced by the larger differences in mean scores between the top and bottom categories.

Table 3 shows mean differences in CES-D scores at baseline associated with individual and neighborhood level predictors after adjustment. Increasing income, older age, and higher level of education were each associated with decreasing levels of depressive symptoms for both genders (Table 3). Hispanic women had significantly higher mean CES-D scores than Caucasian women.

Higher neighborhood score was associated with lower CES-D scores in both men and women after adjusting for

TABLE 2. Mean baseline CES-D score by quartiles of neighborhood characteristics* $(n=2,609)$, the MESA Study 2000-2002

\begin{tabular}{|c|c|c|c|}
\hline $\begin{array}{l}\text { Neighborhood } \\
\text { characteristic }\end{array}$ & Quartile $^{\dagger}$ & $\begin{array}{c}\text { Mean CES-D } \\
\text { Score: Men } \\
(\mathrm{SE})\end{array}$ & $\begin{array}{c}\text { Mean CES-D } \\
\text { Score: Women } \\
(\mathrm{SE})\end{array}$ \\
\hline \multirow[t]{5}{*}{ Social cohesion } & $1 \mathrm{st}$ & $7.96(7.82)$ & $10.54(9.22)$ \\
\hline & $2 \mathrm{nd}$ & $6.62(6.07)$ & $8.59(8.05)$ \\
\hline & $3 r d$ & $6.22(6.49)$ & $8.43(8.43)$ \\
\hline & 4th (most favorable) & $4.98(5.27)$ & $6.46(6.46)$ \\
\hline & $P$ trend & $<0.01$ & $<0.01$ \\
\hline \multirow[t]{5}{*}{ Violence } & 1st (most favorable) & $4.90(5.14)$ & $6.60(6.51)$ \\
\hline & 2nd & $5.56(5.40)$ & $7.68(7.09)$ \\
\hline & $3 \mathrm{rd}$ & $7.67(7.83)$ & $8.96(8.45)$ \\
\hline & 4 th & $7.72(7.03)$ & $10.81(9.03)$ \\
\hline & $P$ trend & $<0.01$ & $<0.01$ \\
\hline \multirow{5}{*}{$\begin{array}{l}\text { Aesthetic } \\
\text { environment }\end{array}$} & 1 st & $8.22(7.69)$ & $10.95(9.33)$ \\
\hline & $2 \mathrm{nd}$ & $6.86(6.47)$ & $8.60(7.87)$ \\
\hline & $3 \mathrm{rd}$ & $5.69(5.94)$ & $8.16(7.45)$ \\
\hline & 4th (most favorable) & $5.13(5.63)$ & $6.32(6.23)$ \\
\hline & $P$ trend & $<0.01$ & $<0.01$ \\
\hline \multirow{5}{*}{$\begin{array}{l}\text { Summary index } \\
\text { ( } Z \text { score })\end{array}$} & 1 st & $8.00(7.49)$ & $10.56(9.20)$ \\
\hline & $2 \mathrm{nd}$ & $7.03(6.92)$ & $9.07(8.07)$ \\
\hline & $3 r d$ & $5.64(5.67)$ & $7.64(7.34)$ \\
\hline & 4th (most favorable) & $5.06(5.47)$ & $6.55(6.30)$ \\
\hline & $P$ trend & $<0.01$ & $<0.01$ \\
\hline
\end{tabular}

CES-D = Center for Epidemiologic Studies-Depression; MESA = Multi-Ethni Study of Atherosclerosis.

*Neighborhood characteristics were measured using Empirical Bayes estimators.

${ }^{\dagger}$ A higher quartile is more favorable for the social cohesion, aesthetic environment, and summary index scales, whereas it is less favorable for the violence scale. 
TABLE 3. Adjusted mean differences in CES-D score associated with individual and neighborhood characteristics at baseline, the MESA Study 2000-2002 $(n=2,609)$

\begin{tabular}{|c|c|c|}
\hline Characteristic & Men* & Women* \\
\hline \multicolumn{3}{|l|}{ Race/ethnicity } \\
\hline Hispanic & $0.28(-1.13,1.68)$ & $1.32(-0.12,2.76)$ \\
\hline African American & $-0.59(-1.48,0.31)$ & $-0.62(-1.57,0.33)$ \\
\hline Caucasian & $* *$ Ref. & Ref. \\
\hline \multicolumn{3}{|l|}{ Age (years) } \\
\hline $45-54$ & $2.62(1.36,3.88)$ & $3.21(1.76,4.67)$ \\
\hline $55-64$ & $1.50(0.27,2.74)$ & $1.20(-0.22,2.63)$ \\
\hline $65-74$ & $1.08(-0.10,2.26)$ & $-1.19(-2.55,0.17)$ \\
\hline $75-84$ & Ref. & Ref. \\
\hline$P$ trend & $<0.01$ & $<0.01$ \\
\hline \multicolumn{3}{|l|}{ Annual income } \\
\hline$<20,000$ & $2.24(0.78,3.70)$ & $4.94(3.34,6.53)$ \\
\hline $20,000-34,999$ & $2.08(0.84,3.32)$ & $2.94(1.51,4.37)$ \\
\hline $35,000-49,999$ & $0.56(-0.59,1.70)$ & $2.11(0.71,3.52)$ \\
\hline $50,000-74,999$ & $0.22(-0.80,1.23)$ & $1.18(-0.22,2.58)$ \\
\hline $75,000+$ & Ref. & Ref. \\
\hline$P$ trend & $<0.01$ & $<0.01$ \\
\hline \multicolumn{3}{|l|}{ Education } \\
\hline$<$ High school & $0.57(-0.93,2.06)$ & $2.58(0.88,4.28)$ \\
\hline Completed high school & $0.60(-0.62,1.82)$ & $1.07(-0.33,2.47)$ \\
\hline $\begin{array}{l}\text { Some college/associate/ } \\
\text { trade }\end{array}$ & $-0.17(-1.28,0.94)$ & $0.48(-0.78,1.75)$ \\
\hline Bachelor degree & $0.29(-0.81,1.38)$ & $0.00(-1.42,1.41)$ \\
\hline $\begin{array}{l}\text { Graduate/professional } \\
\text { degree }\end{array}$ & Ref. & Ref. \\
\hline$P$ trend & 0.24 & $<0.01$ \\
\hline $\begin{array}{l}\text { Neighborhood score } \\
\text { per SD }\end{array}$ & $-1.01(-1.85,-0.17)$ & $-1.08(-1.88,-0.28)$ \\
\hline \multicolumn{3}{|c|}{$\begin{array}{l}\text { CES-D = Center for Epidemiologic Studies-Depression; MESA }=\text { Multi-Ethnic } \\
\text { Study of Atherosclerosis. } \\
\text { *Models include race/ethnicity, age, income, highest education achieved, and } \\
\text { neighborhood summary score. Estimates are therefore adjusted for all the variables } \\
\text { in the table. Mean differences for categorical variables are differences compared } \\
\text { with the reference group for each variable. } \\
* * \text { Ref.= Reference group to which all other levels of the categorical variable are } \\
\text { compared. }\end{array}$} \\
\hline
\end{tabular}

age (mean difference $=-1.76[95 \%$ confidence interval $(\mathrm{CI})=-2.45,-1.08]$ and $-2.49[95 \% \mathrm{CI}=-3.21$, $-1.76]$, respectively) (not shown in table). These associations were reduced but remained statistically significant after additional adjustment for race/ethnicity, income, and education (mean difference $=-1.01[95 \% \mathrm{CI}=-1.85,-0.17]$ and $-1.08[95 \% \mathrm{CI}=-1.88,-0.28]$ in men and women, respectively) (Table 3 ). The associations of neighborhood characteristics with CES-D were consistently stronger in women than in men $(P$ for additive interaction $=0.02)$. When each neighborhood characteristic was examined separately, associations were similar in magnitude and in the expected direction for all three scales (data not shown).

Table 4 shows characteristics of participants who did and did not develop depression (defined as CESD $\geqslant 16$ or use of antidepressant medication) over the follow-up. Of 1,919 persons with no depression at baseline, $12.9 \%$ (248) developed depression over follow-up. Thirty-one of 248 participants with incident depression reported taking antidepressant medications at follow-up. Baseline CES-D scores were lower in men and women who did not develop depression than in those who did. The mean 5 - year increase in CES-D scores among those characterized as developing depression was 7.40 in men and 7.36 in women, whereas scores did not change substantially in those who did not develop depression (mean change $=-0.44$ in men; -0.21 in women) (Table 4). Men and women with incident depression had lower annual income and less education than those without (Table 4). Summary neighborhood scores were lower in participants who developed depression than in those who did not, but differences were small (Table 4).

Table 5 presents associations of individual and neighborhood characteristics with incident depression after adjustment. Younger age and lower income and education were associated with increased odds of developing depression. No associations were observed between neighborhood characteristics and development of depression in men (odds ratio $[\mathrm{OR}]=0.96[95 \% \mathrm{CI}=0.74,1.25])$. An inverse association was observed in women but confidence intervals were wide and included the null value $(\mathrm{OR}=0.89[95 \% \mathrm{CI}=0.63$, 1.26]). The weak longitudinal associations in women disappeared when baseline CES-D score was added to the model (data not shown). Longitudinal analyses were also conducted for each neighborhood characteristic separately. Odds ratios were consistently less than one for men and women, indicating an inverse association of better neighborhood environments with depression, but confidence intervals were wide and included the null value (data not shown).

\section{DISCUSSION}

Depression was associated with neighborhood characteristics in this population-based sample. In cross-sectional analyses, lower levels of neighborhood social cohesion and aesthetic quality and higher levels of neighborhood violence were associated with higher mean CES-D scores in both men and women. Mean CES-D score decreased with increasing levels of the index summary score in both men and women after adjustment for individual-level characteristics. Living in neighborhoods with better neighborhood environments was associated with slightly reduced odds of developing depression among women without depression at baseline, but confidence intervals on these estimates were wide and included the null value.

This study builds on previous research by incorporating direct measures of specific neighborhood characteristics that may affect depression. An important innovation of our study is the use of a sample of informant residents to 
TABLE 4. Selected characteristics of MESA participants who did and did not develop depression (CES-D score $\geqslant 16$ or use of anti-depressant medications) over $4-5$ year follow-up among those with CES-D $<16$ at baseline $(n=1,919)$

\begin{tabular}{|c|c|c|c|c|c|c|}
\hline & \multicolumn{3}{|c|}{ Men } & \multicolumn{3}{|c|}{ Women } \\
\hline & $\begin{array}{c}\text { Developed } \\
\text { depression } \\
(n=98)\end{array}$ & $\begin{array}{l}\text { Did not develop } \\
\text { depression } \\
(n=835)\end{array}$ & $P^{*}$ & $\begin{array}{l}\text { Developed } \\
\text { depression } \\
(n=150)\end{array}$ & $\begin{array}{l}\text { Did not develop } \\
\text { depression } \\
(n=836)\end{array}$ & $P^{*}$ \\
\hline CES-D at baseline (mean (SD)) & $8.11(4.17)$ & $4.66(3.75)$ & $<0.01$ & $9.12(4.24)$ & $4.95(3.85)$ & $<0.01$ \\
\hline 5-year CES-D change (mean (SD)) & $11.73(0.43)$ & $-0.44(0.19)$ & $<0.01$ & $12.33(038)$ & $-0.21(0.22)$ & $<0.01$ \\
\hline \multicolumn{7}{|l|}{ Race/ethnicity (\% distribution) } \\
\hline Caucasian & 22.5 & 14.3 & 0.03 & 24.0 & 12.8 & $<0.01$ \\
\hline African American & 42.9 & 38.8 & & 38.0 & 47.0 & \\
\hline Hispanic & 34.7 & 47.0 & & 38.0 & 40.2 & \\
\hline \multicolumn{7}{|l|}{ Age (years) (\% distribution) } \\
\hline $45-54$ & 33.7 & 25.2 & 0.33 & 34.0 & 26.3 & 0.23 \\
\hline $55-64$ & 27.6 & 29.8 & & 27.3 & 28.2 & \\
\hline $65-74$ & 28.6 & 34.3 & & 28.0 & 34.3 & \\
\hline $75-84$ & 10.2 & 10.8 & & 10.7 & 11.1 & \\
\hline \multicolumn{7}{|l|}{ Annual income (\% distribution) } \\
\hline$<20,000$ & 22.5 & 11.1 & $<0.01$ & 26.7 & 19.6 & 0.19 \\
\hline $20,000-34,999$ & 24.5 & 14.9 & & 25.3 & 24.5 & \\
\hline $35,000-49,999$ & 13.3 & 18.2 & & 17.3 & 18.9 & \\
\hline $50,000-74,999$ & 19.4 & 22.9 & & 18.0 & 17.9 & \\
\hline $75,000+$ & 20.4 & 32.9 & & 12.7 & 19.0 & \\
\hline \multicolumn{7}{|l|}{ Education (\% distribution) } \\
\hline$<$ High school & 28.6 & 10.5 & $<0.01$ & 18.7 & 9.1 & $<0.01$ \\
\hline Completed high school & 15.3 & 17.7 & & 18.7 & 23.3 & \\
\hline Some college/associate/trade & 20.4 & 26.6 & & 34.7 & 32.8 & \\
\hline Bachelor degree & 17.4 & 21.3 & & 17.3 & 17.5 & \\
\hline Graduate/professional degree & 18.4 & 23.8 & & 10.7 & 17.3 & \\
\hline Social cohesion (mean (SD)) & $3.13(0.29)$ & $3.22(0.32)$ & 0.01 & $3.13(0.30)$ & $3.18(0.31)$ & 0.04 \\
\hline Violence (mean (SD)) & $2.00(0.37)$ & $1.88(0.39)$ & $<0.01$ & $2.01(0.39)$ & $1.92(0.38)$ & $<0.01$ \\
\hline Aesthetic environment (mean (SD)) & $3.81(0.42)$ & $3.90(0.43)$ & 0.04 & $3.75(0.44)$ & $3.85(0.45)$ & 0.01 \\
\hline Summary index (mean (SD)) & $-0.14(0.92)$ & $0.14(0.99)$ & 0.01 & $-0.20(0.97)$ & $0.04(0.99)$ & 0.01 \\
\hline
\end{tabular}

CES-D = Center for Epidemiologic Studies-Depression; MESA = Multi-Ethnic Study of Atherosclerosis.

*P compares those who did and did not develop incident depression.

characterize the neighborhoods of study participants. This approach to measuring neighborhood-level factors was originally developed in the social sciences (26) but has been used only recently in epidemiology (24). It has been infrequently used to investigate neighborhood effects on mental health. This approach to measurement is particularly useful when investigating self-reported outcomes (such as depression) where same source bias is a possibility and for constructs (such as social cohesion) that can only be assessed through questionnaires. Using this approach we found that aesthetic quality, violence, and social cohesion were crosssectionally related to depressive symptoms in the expected direction. Echeverria et al. (36) reported similar results for social cohesion using MESA participant reports of neighborhood social cohesion.

Prior cross-sectional investigations of the effects of aesthetic quality, social cohesion, and violence on depression or depressive symptoms have not always yielded consistent results. Four of five studies that investigated measures related to our construct of aesthetic quality [e.g., trash and noise $(37,38)$; homes well-maintained $(16,17)$; attractiveness
(19)] found a significant association. Four of seven studies that investigated effects of neighborhood social cohesion $(9,21,39-43)$ reported that greater social cohesion was associated with lower levels of depression or depressive symptoms. Exposure to violence and related constructs [e.g., fear of calamity (44); crime (42); concerns about police responsiveness (22)] were associated with depressive symptoms in eight of 14 studies $(20-22,37,41,42,44,45)$. Variations across studies may be due in part to differences in the neighborhood-level measures used. We used a reliable scale and used statistical methods that account for measurement error in the neighborhood-level measures (46).

Several prior studies have documented associations of neighborhood characteristics such as neighborhood disorder and cohesiveness with incident depression or increased levels of depressive symptoms $(9,18,38,40,47,48)$. We found some evidence that the neighborhood characteristics examined were also associated with incident depression (at least in women) but associations were not statistically significant. The associations we expect to find are relatively weak ones, so small sample size and short follow-up may have 
TABLE 5. Adjusted OR of incident depression (defined as CES-D score of $\geqslant 16$ or using anti-depressant medications) over 4-5 year follow-up among MESA participants with CES-D scores $<16$ at baseline $(95 \% \mathrm{CI})(n=1,919)$

\begin{tabular}{|c|c|c|}
\hline Characteristic & $\operatorname{Men}(n=933) *$ & Women $(n=986)^{*}$ \\
\hline \multicolumn{3}{|l|}{ Race/ethnicity } \\
\hline Hispanic & $0.76(0.35,1.70)$ & $1.14(0.63,2.07)$ \\
\hline African American & $1.13(0.66,1.92)$ & $0.66(0.43,1.02)$ \\
\hline Caucasian & **Ref. & Ref. \\
\hline \multicolumn{3}{|l|}{ Age (years) } \\
\hline $45-54$ & $2.17(0.96,4.87)$ & $1.98(1.01,3.89)$ \\
\hline $55-64$ & $1.34(0.60,3.01)$ & $1.39(0.71,2.71)$ \\
\hline $65-74$ & $0.98(0.45,2.15)$ & $0.98(0.52,1.86)$ \\
\hline $75-84$ & Ref. & Ref. \\
\hline \multicolumn{3}{|l|}{ Annual income } \\
\hline$<20,000$ & $2.97(1.31,6.72)$ & $2.15(1.03,4.50)$ \\
\hline $20,000-34,999$ & $2.51(1.20,5.26)$ & $1.68(0.87,3.26)$ \\
\hline $35,000-49,999$ & $1.13(0.52,2.46)$ & $1.45(0.74,2.81)$ \\
\hline $50,000-74,999$ & $1.37(0.70,2.69)$ & $1.62(0.85,3.10)$ \\
\hline $75,000+$ & Ref. & Ref. \\
\hline \multicolumn{3}{|l|}{ Education } \\
\hline$<$ High school & $2.14(0.95,4.82)$ & $2.46(1.13,5.38)$ \\
\hline Completed high school & $0.82(0.38,1.78)$ & $1.10(0.55,2.21)$ \\
\hline Some college/associate/trade & $0.69(0.34,1.41)$ & $1.52(0.83,2.81)$ \\
\hline Bachelor degree & $0.84(0.41,1.73)$ & $1.60(0.82,3.14)$ \\
\hline $\begin{array}{l}\text { Graduate/professional } \\
\text { degree }\end{array}$ & Ref. & Ref. \\
\hline Neighborhood score & $0.96(0.74,1.25)$ & $0.89(0.63,1.26)$ \\
\hline
\end{tabular}

CES-D = Center for Epidemiologic Studies-Depression; CI = confidence interval; MESA = Multi-Ethnic Study of Atherosclerosis; OR = odds ratio.

*Models include race/ethnicity, age, income, highest education achieved, and neighborhood summary score.

**Ref.= Reference group to which all other levels of the categorical variable are compared.

limited our ability to detect longitudinal associations. Exposures over long periods may be necessary to affect mental health and the short follow-up period we investigated may not be sufficient to detect an association. The use of depressive symptoms as opposed to a clinical depression measure (as used in some prior work) $(1,17,41,49)$ may also have affected our ability to detect longitudinal associations. Overall, participants were quite stable over follow-up ( $80 \%$ did not move between baseline and the time of the last CES-D measurement). Time varying neighborhood exposures were not available so only baseline measures of neighborhood characteristics were investigated.

Cross-sectional associations may be biased because people who are depressed tend to stay in neighborhoods with negative characteristics, whereas those with better mental and physical health are more likely to move out of such areas. However, in our data, most participants reported living in the same neighborhood for a median 17 of years at baseline. If neighborhood characteristics are relatively constant over time (and we have evidence that at least the census characteristics of MESA neighborhoods were highly correlated over the 20 years before the MESA exam) the cross-sectional associations may reflect the effects of these cumulative long-term exposures on the development of depression better than the longitudinal analyses.

Causal inference from an observational study is dependent on the exchangeability of exposed and unexposed participants. We addressed this problem to the extent possible in an observational design by controlling for a set of individual-level factors that might be associated with both depressive symptoms and neighborhood environments. People who have high levels of depressive symptoms might be less likely than those with lower levels to participate in health-related studies. If participation is also associated with neighborhood characteristics such that participation rates are differentially lower among depressed persons living in disadvantaged neighborhoods, we may have underestimated the association between neighborhoods and depressive symptoms.

The use of census tracts as proxies for the geographic area relevant to depression is a limitation of our study. It is plausible that smaller geographic areas are more relevant than the census tracts we examined. This misspecification of the relevant geographic area could have resulted in underestimates of the effects of interest. Other potentially important characteristics that differed between our three study sites, such as rurality, were not considered in this study. This is a potential limitation of our results, although an interaction term between study site and our neighborhood variables was nonsignificant. We also were unable to examine interactions between neighborhood characteristics and life events: it may be that stressful neighborhood conditions interact with negative life events to cause depression (8).

Although the cross-sectional associations we detected may seem small, they are nontrivial. Neighborhoods (crudely defined by census tracts) accounted for $9.8 \%$ and $7.8 \%$ of the total variance in men and women respectively, whereas the individual-level variables examined explained $11.8 \%$ and $4.7 \%$ of the variance. In the full cross-sectional model, the associations between neighborhood characteristics and depressive symptoms are roughly the same magnitude as the associations of CES-D with individual-level education and income (comparing the lowest to the highest groups) (Table 3). Interestingly our results are consistent with results of the Moving To Opportunity randomized trial, which found that adults and female youth who moved from poor to non-poor neighborhoods experienced mental health benefits (50).

Depression has both health and economic consequences, and worsens the health outcomes of comorbid conditions $(51,52)$. If neighborhood features influence risk of depression apart from individual risk factors, interventions aimed at improving neighborhood environments will be a key component in reducing the burden of depression. Our results show that aesthetic quality, violence, and social cohesion are important candidates for future investigation. 
This work was supported by R01 HL071759 (Diez Roux). MESA was supported by contracts N01-HC-95159-95165 from the National Heart, Lung, and Blood Institute. The authors thank the other investigators, the staff, and the participants of the MESA study for their valuable contributions. A full list of participating MESA investigators and institutions can be found at http://www.mesa-nhlbi.org.

\section{REFERENCES}

1. Silver E, Mulvey EP, Swanson JW. Neighborhood structural characteristics and mental disorder: Faris and Dunham revisited. Soc Sci Med. 2002;55:1457-1470.

2. Wainwright NW, Surtees PG. Places, people, and their physical and mental functional health. J Epidemiol Community Health. 2004;58:333-339.

3. Wainwright NW, Surtees PG. Area and individual circumstances and mood disorder prevalence. Br J Psychiatry. 2004;185:227-232.

4. Skapinakis P, Lewis G, Araya R, Jones K, Williams G. Mental health inequalities in Wales, UK: multi-level investigation of the effect of area deprivation. Br J Psychiatry. 2005;186:417-422.

5. Kubzansky LD, Subramanian SV, Kawachi I, Fay ME, Soobader MJ, Berkman LF. Neighborhood contextual influences on depressive symptoms in the elderly. Am J Epidemiol. 2005;162:253-260.

6. Ross C. Neighborhood disadvantage and adult depression. J Health Soc Behav. 2000;41:177-187.

7. Ostir GV, Eschbach K, Markides KS, Goodwin JS. Neighborhood composition and depressive symptoms among older Mexican Americans. J Epidemiol Community Health. 2003;57:987-992.

8. Cutrona CE, Russell DW, Brown PA, Clark LA, Hessling RM, Gardner KA. Neighborhood context, personality, and stressful life events as predictors of depression among African American women. J Abnorm Psychol. 2005;114:3-15.

9. Xue Y, Leventhal T, Brooks-Gunn J, Earls FJ. Neighborhood residence and mental health problems of 5- to 11-year-olds. Arch Gen Psychiatry. 2005;62:554-563.

10. Reijneveld SA, Schene AH. Higher prevalence of mental disorders in socioeconomically deprived urban areas in The Netherlands: community or personal disadvantage? J Epidemiol Community Health. 1998;52:2-7.

11. Weich S, Twigg L, Holt G, Lewis G, Jones K. Contextual risk factors for the common mental disorders in Britain: a multilevel investigation of the effects of place. J Epidemiol Community Health. 2003;57:616-621.

12. Henderson C, Diez Roux AV, Jacobs DR Jr, Kiefe CI, West D, Williams DR. Neighborhood characteristics, individual level socioeconomic factors, and depressive symptoms in young adults: the CARDIA study. J Epidemiol Community Health. 2005;59:322-328.

13. Weich S, Twigg L, Lewis G, Jones K. Geographical variation in rates of common mental disorders in Britain: prospective cohort study. Br J Psychiatry. 2005;187:29-34.

14. Oakes JM, Rossi PH. The measurement of SES in health research: current practice and steps toward a new approach. Soc Sci Med. 2003;56:769-784.

15. Diez Roux AV. Estimating neighborhood health effects: the challenges of causal inference in a complex world. Soc Sci Med. 2004;58:1953-1960.

16. Weich S, Blanchard M, Prince M, Burton E, Erens B, Sproston K. Mental health and the built environment: cross-sectional survey of individual and contextual risk factors for depression. Br J Psychiatry. 2002;180:428-433.

17. Galea S, Ahern J, Rudenstine S, Wallace Z, Vlahov D. Urban built environment and depression: a multilevel analysis. J Epidemiol Community Health. 2005;59:822-827.

18. Latkin CA, Curry AD. Stressful neighborhoods and depression: a prospective study of the impact of neighborhood disorder. J Health Soc Behav. 2003;44:34-44.
19. Hadley-Ives ES, Elze D, Johnson S, Dore P. Measuring neighborhood and school environments: perceptual and aggregate approaches. J Hum Behav Soc Environ. 2000;3:1-28.

20. Fitzpatrick KM, Piko BF, Wright DR, LaGory M. Depressive symptomatology, exposure to violence, and the role of social capital among African American adolescents. Am J Orthopsychiatry. 2005;75:262-274.

21. Aneshensel CS, Sucoff CA. The neighborhood context of adolescent mental health. J Health Soc Behav. 1996;37:293-310.

22. Schulz AJ, Israel BA, Zenk SN, Parker EA, Lichtenstein R, Shellman Weir S, et al. Psychosocial stress and social support as mediators of relationships between income, length of residence and depressive symptoms among African American women on Detroit's east side. Soc Sci Med. 2006;62:510-522.

23. Mair C, Diez Roux AV, Galea S. Are neighborhood characteristics associated with depressive symptoms? A review of evidence. J Epidemiol Community Health. 2008;62:940-946.

24. Mujahid MS, Diez Roux AV, Morenoff JD, Raghunathan T. Assessing the measurement properties of neighborhood scales: from psychometrics to ecometrics. Am J Epidemiol. 2007;165:858-867.

25. Bild DE, Bluemke DA, Burke GL, Detrano R, Diez Roux AV, Folsom AR, et al. Multi-ethnic study of atherosclerosis: objectives and design. Am J Epidemiol. 2002;156:871-881.

26. Raudenbush SW, Sampson RJ. Ecometrics: toward a science of assessing ecological settings, with application to the systematic social observation of neighborhoods. Sociol Methodol. 1999;29:1-41.

27. Radloff L. The CES-D scale: a self-report depression scale for research in the general population. Appl Psychol Measurement. 1977;1:385-401.

28. Sampson RJ. The neighborhood context of well-being. Perspect Biol Med. 2003;46:S53-64.

29. Ulrich RS. View through a window may influence recovery from surgery. Science. 1984;224:420-421.

30. Groenewegen PP, van den Berg AE, de Vries S, Verheij RA, Vitamin G. effects of green space on health, well-being, and social safety. BMC Public Health. 2006;6:149.

31. Weissman MM, Klerman GL. Sex differences and the epidemiology of depression. Arch Gen Psychiatry. 1977;34:98-111.

32. Reinsch $\mathrm{CH}$. Smoothing by spline functions. Numerische Mathematik. 1967;10:177-183.

33. Mujahid M, Diez Roux A, Morenoff J, Raghunathan T, Cooper R, Ni H, et al. Neighborhood characteristics and hypertension. Epidemiology. 2008;19:590-598.

34. Carson AP, Rose KM, Catellier DJ, Kaufman JS, Wyatt SB, Diez-Roux AV, et al. Cumulative socioeconomic status across the life course and subclinical atherosclerosis. Ann Epidemiol. 2007;17:296-303.

35. Sanchez BN, Raghunathan TE, Diez Roux AV, Zhu Y, Lee O. Combining data from primary and ancillary surveys to assess the association between neighborhood-level characteristics and health outcomes: the Multi-Ethnic Study of Arthrosclerosis. Stat Med. 2008;27:5745-5763.

36. Echeverria S, Diez-Roux AV, Shea S, Borrell LN, Jackson S. Associations of neighborhood problems and neighborhood social cohesion with mental health and health behaviors: the Multi-Ethnic Study of Atherosclerosis. Health Place. 2008;14:853-865.

37. Yen IH, Yelin EH, Katz P, Eisner MD, Blanc PD. Perceived neighborhood problems and quality of life, physical functioning, and depressive symptoms among adults with asthma. Am J Public Health. 2006;96:873-879.

38. Schieman S, Meersman SC. Neighborhood problems and health among older adults: received and donated social support and the sense of mastery as effect modifiers. J Gerontol B Psychol Sci Soc Sci. 2004;59:S89-97.

39. Gary TL, Stark SA, Laveist TA. Neighborhood characteristics and mental health among African Americans and whites living in a racially integrated urban community. Health Place. 2007;13:569-575. 
40. Gutman LM, Sameroff AJ. Continuities in depression from adolescence to young adulthood: contrasting ecological influences. Dev Psychopathol. 2004;16:967-984.

41. Cutrona CE, Russell DW, Hessling RM, Brown PA, Murry V. Direct and moderating effects of community context on the psychological well-being of African American women. J Pers Soc Psychol. 2000;79:1088-1101.

42. Simons RL, Murry V, McLoyd V, Lin KH, Cutrona C, Conger RD. Discrimination, crime, ethnic identity, and parenting as correlates of depressive symptoms among African American children: a multilevel analysis. Dev Psychopathol. 2002;14:371-393.

43. Steptoe A, Feldman PJ. Neighborhood problems as sources of chronic stress: development of a measure of neighborhood problems, and associations with socioeconomic status and health. Ann Behav Med. 2001;23:177-185.

44. Stevenson HC. Raising safe villages: Cultural-ecological factors that influence the emotional adjustment of adolescents. J Black Psychol. 1998;24:44-59.

45. Natsuaki MN, Ge X, Brody GH, Simons RL, Gibbons FX, Cutrona CE. African American children's depressive symptoms: the prospective effects of neighborhood disorder, stressful life events, and parenting. Am J Community Psychol. 2007;39:163-176.
46. Sanchez BN, Raghunathan TE, Diez Roux AV, Zhu Y, Lee O. Combining data from primary and ancillary surveys to assess the association between neighborhood-level characteristics and health outcomes: the Multi-Ethnic Study of Atherosclerosis. Stat Med. 2008;27:5745-5763.

47. Christie-Mizell CA, Steelman LC, Stewart J. Seeing their surroundings: the effects of neighborhood setting and race on maternal distress. Soc Sci Res. 2003;32:402-428.

48. Forehand R, Jones DJ. Neighborhood violence and co-parent conflict: interactive influence on child psychosocial adjustment. J Abnorm Child Psychol. 2003;31:591-604.

49. Tweed DL, Goldsmith HF, Jackson DJ, Stiles D, Rae DS, Kramer M. Racial congruity as a contextual correlate of mental disorder. Am J Orthopsychiatry. 1990;60:392-403.

50. Kling JR, Liebman JB, Katz LF. Experimental analysis of neighborhood effects. Econometrica. 2007;75:83-119.

51. Moussavi S, Chatterji S, Verdes E, Tandon A, Patel V, Ustun B. Depression, chronic diseases, and decrements in health: results from the World Health Surveys. Lancet. 2007;370:851-858.

52. Prince M, Patel V, Saxena S, Maj M, Maselko J, Phillips MR, et al. No health without mental health. Lancet. 2007;370:859-877. 